\section{Naltrexone for 3 or 12 months did not reduce drinking in alcohol dependence}

Krystal JH, Cramer JA, Krol WF, et al, for the Veterans Affairs Naltrexone Cooperative Study 425 Group. Naltrexone in the treatment of alcohol dependence. N Engl J Med 2001 Dec 13;345:1734-9.

\section{QUESTION: In patients with alcohol dependence and a recent history of drinking to intoxication, is treatment with naltrexone for 3 or 12 months in addition to standardised psychosocial treatment more effective than placebo for reducing alcohol consumption?}

\section{Design}

Randomised \{allocation concealed*\}†, blinded (participants and health care providers),* controlled trial with 52 weeks of follow up.

\section{Setting}

15 Veterans Affairs medical centres in the US.

\section{Patients}

627 outpatients (mean age 49 y, 98\% men) who had a diagnosis of alcohol dependence according to the Diagnostic and Statistical Manual of Mental Disorders, 4th ed, criteria; who had not drunk for $\geqslant 5$ days; and who had a recent history of drinking to intoxication $(\geqslant 6$ drinks for men and $\geqslant 4$ drinks for women at least twice during a $1 \mathrm{wk}$ period in the $30 \mathrm{~d}$ before screening). Exclusion criteria included previous use of naltrexone and other substance abuse or dependence. Follow up was $90 \%$ and $93 \%$ at 13 and 52 weeks, respectively.

\section{Intervention}

209 patients each were allocated to naltrexone, $50 \mathrm{mg}$ once daily, for 3 months (short term group); naltrexone, $50 \mathrm{mg}$ once daily, for 12 months (long term group); or placebo. All patients received individual 12 step facilitation counselling for 13 months and were encouraged to attend Alcoholics Anonymous meetings. Visits were weekly for 16 weeks, every 2 weeks during weeks 17 to 36 , and monthly during weeks 37 to 56 .

\section{Main outcome measures}

Time to relapse ( $\mathrm{d}$ from randomisation to first $\mathrm{d}$ of heavy drinking) during the first 3 months, percentage of drinking days (PDD), and number of drinks per drinking day (NDPDD) for a 12 month period.

\section{Main results}

Analysis was by intention to treat. At 13 weeks, the combined short term and long term naltrexone groups did not differ from the placebo group for time to relapse (table). At 52 weeks, the short term and long term naltrexone groups did not differ from the placebo group for PDD or NDPDD (NDPDD evaluated for the $66 \%$ of patients who consumed alcohol during follow up) (table).

\section{Conclusion}

In patients with alcohol dependence and a recent history of drinking to intoxication, treatment with naltrexone for 3 or 12 months in addition to standardised psychosocial treatment was no more effective than placebo for reducing alcohol consumption.
*See glossary.

$\dagger$ Information provided by author.
Sources of funding:

Department of Veterans Affairs Office of Research and Development and Dupont

Pharmaceuticals.

For correspondence: Dr J H Krystal, Veterans Affairs Connecticut Healthcare System, West Haven, Connecticut, USA. john.krystal@yale.edu.

Abstract and commentary also appear in Evidence-Based Mental Health.

Naltrexone for 3 months (short term) or 12 months (long term) v placebo for alcohol dependence

\begin{tabular}{|c|c|c|c|}
\hline Outcomes at 13 weeks & Comparison & Means & $\begin{array}{l}\text { Difference between } \\
\text { groups }(95 \% \mathrm{CI})\end{array}$ \\
\hline Number of days to relapse & $\begin{array}{l}\text { Short or long } \\
\text { term } v \text { placebo }\end{array}$ & $\begin{array}{l}72.3 v \\
62.4\end{array}$ & $9.9(-3.0$ to 22.8$)$ \\
\hline \multicolumn{4}{|l|}{ Outcomes at 52 weeks } \\
\hline \multirow{2}{*}{ Percentage of drinking days } & $\begin{array}{l}\text { Long term } v \\
\text { placebo }\end{array}$ & $\begin{array}{l}15.1 v \\
18.0\end{array}$ & $-2.9(-7.7$ to 1.9$)$ \\
\hline & $\begin{array}{l}\text { Short term } v \\
\text { placebo }\end{array}$ & $\begin{array}{l}19.4 v \\
18.0\end{array}$ & $1.4(-3.6$ to 6.5$)$ \\
\hline \multirow{2}{*}{$\begin{array}{l}\text { Number of drinks per drinking day } \\
\text { (NDPDD)§ }\end{array}$} & $\begin{array}{l}\text { Long term } v \\
\text { placebo }\end{array}$ & $9.6 \vee 9.3$ & $0.3(-1.8$ to 2.4$)$ \\
\hline & $\begin{array}{l}\text { Short term } v \\
\text { placebo }\end{array}$ & $10.5 v 9.3$ & $1.2(-0.5$ to 2.9$)$ \\
\hline
\end{tabular}

Cl defined in glossary None of the mean differences are statistically significant.

SNDPDD evaluated for the $66 \%$ of patients who consumed alcohol during follow up.

\section{COMMENTARY}

2 meta-analyses have supported the effectiveness of naltrexone in treating alcohol dependence. ${ }^{12} 2$ further studies showing its efficacy have since been published. ${ }^{3}{ }^{4}$ The negative study by Krystal $e t a l$ and the 2 negative studies in the meta-analysis by Streeton and Whelan ${ }^{1}$ are the only truly multicentre studies in which naltrexone or placebo was offered in addition to standard abstinence oriented treatment programmes.

Although no large trial of naltrexone has used coping skills therapy (CST), naltrexone has shown efficacy when adjunctive CST has been used in small studies. Fuller and Gordis ${ }^{5}$ comment that CST differs from the 12 step facilitation therapy (used in this study) because a lapse to drinking is dedramatised in CST, with harm-free drinking being seen as an acceptable goal.

Standard end points for treatment trials of patients with alcoholism, including PDD and NDPDD, were used in this study. However, some investigators consider that naltrexone has an effect in reducing the number of days of heavy drinking ( $>5$ drinks). Under this assumption, NDPDD blurs the distinction between those who sometimes drink a little and sometimes drink a lot and those who drink equally frequently but who usually consume moderate amounts. The negative result of this study can be seen as an example of how results of treatment trials weaken when extrapolated outside specialised research centres; it can also be seen as support for further trials of opiate antagonist treatment with alternative types of adjunctive psychotherapy.

Jonathan Chick, MA, MPhil, FRCPsych Royal Edinburgh Hospital, Edinburgh, Scotland, UK

1 Streeton C, Whelan G. Naltrexone, a relapse prevention maintenance treatment of alcohol dependence: a meta-analysis of randomized controlled trials. Alcohol Alcohol 2001;36:54452.

2 Kranzler H, Van Kirk J. Efficacy of naltrexone and acamprosate for alcoholism treatment: a meta-analysis. Alcohol Clin Exp Res 2001;25:1335-41.

3 Morris PL, Hopwood M, Whelan G, et al. Naltrexone for alcohol dependence: a randomised controlled trial. Addiction 2001;96:1565-73.

4 Heinälä P, Alho H, Kiianmaa K, et al. Targeted use of naltrexone without prior detoxification in the treatment of alcohol dependence: a factorial double-blind, placebo-controlled trial. J Clin Psychopharmacol 2001;21:287-92.

5 Fuller RK, Gordis E. Naltrexone treatment for alcohol dependence. $N$ Engl J Med 2001;13:1770-1. 